\title{
Hevosenlannan tuubikompostointi
}

\author{
Elina Virkkunen ${ }^{1)}$, Tiina Karppinen ${ }^{2)}$, Henri Karjalainen ${ }^{3)}$, Pekka Heikkinen ${ }^{1)}$ ja Jukka Kemppainen ${ }^{1)}$ \\ ${ }^{1)}$ MTT Sotkamo, Kipinäntie 16, 88600 Sotkamo, etunimi.sukunimi@mtt.fi \\ ${ }^{2)} J y v a ̈ s k y l a ̈ n ~ y l i o p i s t o$, Bio- ja ympäristötieteiden laitos, Survontie 9, 40500 Jyväskylä, \\ tiina.k.m.karppinen@student.jyu.fi, \\ 3) Jyväskylän yliopisto, Bio- ja ympäristötieteiden laitos, Survontie 9, 40500 Jyväskylä, \\ henri.e.karjalainen@student.jyu.fi
}

\section{Tiivistelmä}

Hevosenlannan hyödyntäminen lannoitteena on haastavaa suuren kuivikepitoisuuden ja alhaisen typpipitoisuuden vuoksi. Puupohjainen kuivike hidastaa lannan hajoamista ja sitoo pellon typpivaroja. Kompostointi parantaa lannan ominaisuuksia, mutta perinteinen aumakompostointi vaatii kalliin pohjaratkaisun ja paljon tilaa.

Tuubikompostit voidaan rakentaa suoraan tasaiselle peltomaalle, eikä tiivistä pohjarakennetta tarvita. Kompostoitava materiaali pakataan erityisellä pakkauslaitteella muovikalvon sisään pitkäksi pötköksi. Muovikalvon on tarkoitus pitää kompostin valumat sisällään. Tuubikompostien sisään syötetään rakennusvaiheessa kaksi tuubin pituussuunnassa kulkevaa salaojaputkea, joiden kautta kompostiin pääsee ilmaa.

MTT Sotkamon tutkimusasemalla rakennettiin kesällä 2012 kuusi tuubikompostia. Kokeessa selvitettiin hevosenlannan soveltuvuutta tuubikompostointiin sekä menetelmän käyttökelpoisuutta. Kompostoitavat materiaalit olivat eri tavoin kuivitettua hevosenlantaa. Lisäksi purukuivitettua hevosenlantaa sekoitettiin kananlantaan, naudanlantaan ja biojätteen biokaasutuksessa saatuun käsittelyjäännökseen.

Viiden kompostin lämpötilat jäivät varsin alhaisiksi. Purukuivitettu hevosenlanta oli todennäköisesti jo osittain kompostoitunutta tuubikompostoinnin alkaessa. Kuudennen kompostin raakaaineena oli muita komposteja tuoreempi hevosenlanta, ja sen lämpötilat kohosivat huomattavasti toisia tuubikomposteja korkeammalle.

Suurin hankaluus tuubikompostoinnissa on riittävän ilmastuksen varmistaminen. Ilmastuksen tehostamiseksi tuubien kylkiin viillettiin palkeenkieliä ja tuubeja ilmastettiin ensimmäisenä vuonna koneellisesti. Ilmastus ei nostanut lämpötiloja merkittävästi korkeammalle tasolle.

Hevosenlannan typpipitoisuus oli kokeen alussa matala. Olki-turvekuivitetussa lannassa oli hevosenlantakomposteista eniten kokonaistyppeä. Sen sijaan tuoreessa pellettikuivitetussa lannassa liukoisen typen osuus oli korkein.

Kun tuubit olivat kompostoituneet vuoden, kaikkien kompostien typpipitoisuudet olivat laskeneet. Viljelykäytössä kompostin optimaalinen hiili-typpisuhde on alle 20. Ainoastaan olkiturvekuivitetulla hevosenlannalla se oli 15,5. Korkein hiili-typpisuhde 38,6, oli hevosen purulannalla. Hiili-typpisuhde oli laskenut vuoden kompostoinnin aikana hevosen- ja kananlannan seosta lukuun ottamatta kaikilla materiaaleilla.

Tuubikompostoidun hevosen purulannan lannoituskäyttöä testattiin kesällä 2013 peltoviljelykokeessa. Suojaviljaan kylvettyä nurmea lannoitettiin pelkällä lantakompostilla, typpilannoituksella täydennetyllä lantakompostilla ja väkilannalla. Mukana oli myös lannoittamaton ruutu. Suojaviljana olleesta ohrasta saatiin hyvä sato, samoin väkilannoitetulla ruudulla ja typellä täydennetyllä kompostiruudulla. Myös pelkkä komposti toimi lannoitteena melko hyvin. Koetta jatketaan kesällä 2014.

Tutkimus on osa MTT Sotkamon Biojäte ja hepolanta -hanketta, jota rahoittaa Euroopan aluekehitysrahasto Kainuun ELY-keskuksen kautta.

Asiasanat: Hevosenlanta, tuubikompostointi, kompostointi, kompostin kypsyys 


\section{Johdanto}

Hevosenlanta sisältää kuiviketta 60 - 80 prosenttia. Mikäli kuivike on puupohjaista, lanta soveltuu huonosti peltolevitykseen, koska se sitoo hajotessaan typpeä. (Pesonen, ym. 2008). Tällainen lanta vaatii pitkän kompostoitumisajan ennen pellolle levittämistä. Jos puupohjaisen kuivikkeen osuus on pieni, ja kuivike on pääasiassa turvetta tai olkea, lanta kompostoituu paremmin. Se voidaan myös levittää pellolle sellaisenaan.

Lanta alkaa kompostoitua jo lantalassa. Se voidaan sen jälkeen kompostoida patterissa pellolla. Muita vaihtoehtoja kompostointiin ovat rumpukompostori tai lannan pakkaaminen muovituubiin. Tuubikompostointi on uudehko kompostointimenetelmä, jossa lantaa pakataan pitkään aumamuoviputkeen erityisellä traktoriin kytkettävällä pakkausvaunulla. Massa pienenee noin kolmanneksen ja muuttuu hygieeniseksi, tasalaatuiseksi sekä hajuttomaksi. Ravinnehävikit jäävät aiemman tiedon perusteella tässä kompostointimenetelmässä pieniksi. Tuubikompostoinnissa ei tarvita eristettyä pohjaa tai valuma-allasta, vaan tasainen alusta riittää. Tuubikompostointi sopii viljelijälle tai koneurakoijalle, joka on valmis investoimaan pakkausvaunuun ja jolla on lannalle levityskohde. (Holmen 2010)

Kompostoituminen voidaan jakaa mesofiiliseen, termofiiliseen ja stabiloitumisen vaiheeseen. Mesofiilisessä vaiheessa lämpötila ei vielä kohoa. Kompostoituminen sitoo happea, helposti hajoavat orgaaniset aineet hajoavat ja $\mathrm{pH}$ nousee. Termofiilisessä vaiheessa lämpötila nousee nopeasti, proteiinit hajoavat, $\mathrm{pH}$ nousee ja hiilidioksidia ja ammoniakkia vapautuu. Sitten lämpötila laskee, kuituaineet hajoavat ja alkaa kompostin stabiloituminen ja jälkikypsyminen. Stabiili komposti on hajonnut niin pitkälle, että sen hiilidioksidin tuotto ja hapenkulutus ovat vähentyneet huomattavasti. (Itävaara ym. 2006)

Kypsä komposti on hyvälaatuista ja käyttökelpoista. Sen sisältämä orgaaninen aines on hajonnut riittävän pitkälle, se ei estä kasvien kasvua eikä haise. Kypsyyden määritteleminen on kuitenkin monimutkaista, sillä monet seikat yhdessä vaikuttavat kompostin laatuun. Kompostointiprosessin välituotteet (esim. haihtuvat rasvahapot) kertovat kompostin kypsyyden puutteista ja voivat aiheuttaa kasvitoksisuutta. Kypsä komposti on stabiili eli sen mikrobiologinen aktiivisuus on pysyvästi laskenut alhaiselle tasolle. (Epstein 1997)

Tutkimukset lannan tuubikompostoinnista, kompostin ominaisuuksista ja lannoitusvaikutuksesta sisältyvät Biojäte ja hepolanta -hankkeeseen. Hanketta rahoittaa pääasiallisesti Kainuun ELY-keskus ja Euroopan aluekehitysrahasto. Muita rahoittajia ovat MTT, Kainuun jätehuollon kuntayhtymä Ekokymppi, Aimo Kortteen Konepaja Oy, Metso Automation Oy, Maatalouskoneiden tutkimussäätiö, Pölkky Oy, Suomen Ratsastajainliitto, Kainuun maa- ja metsäsäätiö, Sotkamon kunta, MTK-Sotkamo ja Agrimarket.

\section{Aineisto ja menetelmät}

\section{Tuubikompostointi}

Tutkimuksessa kokeiltiin eri tavoin kuivitetun hevosenlannan kompostoitumista muovituubeissa. Vertailun vuoksi kompostoitiin myös lantaseoksia. Tutkimuksessa haluttiin myös tehdä tunnetuksi tuubikompostointimenetelmää ja kokeilla sen toimivuutta. Kompostit tehtiin MTT Sotkamossa.

Koetta varten Aimo Kortteen Konepaja Oy:ltä lainattiin traktorikäyttöinen MurskaBiopacker, jolla tuubit täytettiin. Sen tehontarve on $85 \mathrm{~kW}$. MurskaBiopackerissa on halkaisijaltaan $570 \mathrm{~mm}: \mathrm{n}$ pakkaajaruuvit, pakkaustiukkuuden säätöjarru, hydraulijarrut ja ilmajousitettu alusta (Anon. 2013).

Lanta kuormattiin traktorin etukauhalla pakkauskoneen syöttösuppiloon, josta syöttöpöytä kuljettaa sen järeille pakkausruuveille ja siitä edelleen muovituubiin. Muovituubin musta pinta tulee ulospäin, jolloin aurinko lämmittää kompostin pintaa ja edistää kompostoitumista. Tuubin halkaisija on 2 metriä, ja rakennusvaiheessa siihen syötetään kaksi salaojaputkea kompostimassan ilmastusta varten. Tuubien kylkiin tehtiin palkeenkieliä ilman kulkua helpottamaan 19.6.2012 ja tuubeja ilmastettiin myös koneellisesti kolmesti viikossa puolen tunnin ajan 2.7.2012 alkaen. Käytössä oli useita puhaltimia, joista Ventur GMT-poistopuhallin osoittautui tehokkaimmaksi. 
Jokainen koemassa pakattiin omaan tuubiinsa. Tuubien kokonaispituus oli 20 metriä. Niiden päihin pakattiin 5 metrin pituinen pätkä hevosen purulantaa, ja tuubin keskelle 10 m pitkä pätkä tutkittavaa näytettä. Koeolosuhteet olivat siten samanlaiset jokaisella tutkittavalla näytteellä. Mikäli näytekompostiin haluttiin kahta eri materiaalia, ne sekoitettiin tuubia pakatessa kuormaamalla eri materiaalit vuorotellen.

Koetuubit: 1. Kananlanta : hevosen purulanta (1:2)

2. Olkipelletti-turvekuivitettu hevosenlanta

3. Naudanlanta : hevosen purulanta (1:1)

4. Hevosen purulanta

5. Hevosen purulanta : biokaasulaitoksen mädäte (5:1)

6. Hevosen puupellettilanta, tuore

Viisi tuubia rakennettiin 22.5. - 25.5.2012. Kuudes tuubikomposti perustettiin vasta syyskuun 2012 puolivälissä. Muissa tuubikomposteissa kompostoitu purukuivitettu hevosenlanta oli jo osittain kompostoitunut avolantalassa sen saapuessa tutkimusasemalle. Tämän vuoksi koettiin tarpeelliseksi perustaa vielä yksi tuubikomposti, johon hankittiin mahdollisimman tuoretta puupellettikuivitettua hevosenlantaa.

Tuubikompostien lämpötiloja seurattiin molempina kesinä (2012 ja 2013) säännöllisesti kaksi kertaa viikossa. Tuubeista mitattiin lämpötilat kolmesta eri mittauspisteestä (pohjois- ja eteläpuolelta sekä tuubin päältä) tuubin keskelle merkatun 10 metrin pätkästä. Pinta- ja syvälämpötilojen erot huomioitiin mittaamalla lämpötilat 20 senttimetrin ja 100 senttimetrin syvyydeltä jokaisesta kolmesta mittauspisteestä. Lämpötilat mitattiin Temppi-150 -aumalämpötilamittarilla. Kompostit olivat toukokuussa 2013 vielä laajalti jäässä pintakerrosta lukuun ottamatta. Näytteet onnistuttiin kuitenkin kairaamaan myös metrin syvyydestä kompostin sisäosista.

\section{Laboratoriomääritykset}

Jokaisesta kompostointimateriaalista lähetettiin näyte MTT Jokioisten laboratorioon analysoitavaksi ennen kompostoinnin aloittamista kesällä 2012 ja toinen näyte vuoden päästä 3.5.2013. Kompostimateriaalia otettiin jokaisesta tuubikompostista vähintään viisi litraa neljästä näytteenottopaikasta eri puolilta kompostituubia. Nämä sekoitettiin keskenään, ja kokoomanäytteestä otettiin kaksi litran näytettä analyysejä varten. Kompostituubien annetaan jälkikompostoitua vielä toinen vuosi, ja viimeiset määritykset tehdään kesällä 2014. Kuiva-aine eli TS määritettiin kuivaamalla näytettä 105 celsiusasteessa yön yli. pH mitattiin laitteella Mettler Toledo $345 \mathrm{pH}$ meter. Kokonaistyppi ja liukoinen typpi määritettiin Kjeldahl-menetelmällä (Agrifood Research Finland accredited methods 1120, 1122 and 1125 Kjeldahl). Kokonaisfosfori määritettiin kuningasvesiuutolla, ja perustuu standardeihin SFS-ISO 11466 Soil quality sekä ICP-mittauksella. C /N - suhde määritettiin Leco CN-2000 analysaattorilla.

Kompostin kypsyyttä arvioitiin hevosen purulannasta (tuubi 4) määrittämällä haihtuvia rasvahappoja. Ne määritettiin kompostinäytteestä kaasukromatografilla, jossa on liekki-ionisaatiodetektori. Lyhyen aikavälin kasvitoksisuuskokeita tehtiin vihanneskrassilla ja kiinankaalilla. Kymmenen siementä laitettiin kullekin petrimaljalle suodatinpaperin päälle ja maljoja käsiteltiin kompostivesiliuoksella, josta oli neljä eri versiota kompostinpitoisuuden mukaan. Viides käsittelyryhmä oli kontrolli, jota kasteltiin pelkällä tislatulla vedellä.

\section{Lannoituskoe}

Peltoviljelykokeessa pyrittiin selvittämään hevosenlantakompostin hyötykäyttömahdollisuutta lannoitteena nurmella ja viljakasvilla. Koeruuduille (ruudun koko $15 \mathrm{~m}^{2}$ ) kylvettiin nurmi, jonka suojaviljana oli ohra. Lannoitusvaihtoehtoja oli neljä: 1) väkilannoitus

2) kompostilannoitus, väkilannoituksella täydennetty

3) kompostilannoitus

4) kokonaan lannoittamatta jättäminen. 
Koealueelta otettiin maanäytteet, jotka analysoitiin Viljavuuspalvelussa. Lannoitustarve laskettiin VISU-ohjelmalla. Hevosen purulantakompostia voitiin levittää 60 tonnia hehtaarille. Sallittu fosforimäärä tuli tällöin täyteen, mutta typpimäärä jäi huomattavan vajaaksi. Väkilannoitteena käytettiin Yara Bela Suomensalpietaria, jota levitettiin 163 kg hehtaaria kohden. Väkilannoitettujen ruutujen kaliumtaso nostettiin yhtä suureksi kompostin kaliumpitoisuuden kanssa lisäämällä kaliumsuolaa 334 kg hehtaaria kohden. Kustakin lannoitusvaihtoehdosta tehtiin neljä kerrannetta.

Kokeen etenemistä seurattiin viljan ja nurmen kasvun tarkkailulla (pituuskasvu, lehtivihreä) sekä maaperämittauksilla. Ohran sato korjattiin syksyllä 2013. Nurmi korjataan kesällä 2014, joten koe on vielä kesken.

\section{Tulokset ja tulosten tarkastelu}

\section{Lämpötila}

Tuubien lämpötilat jäivät melko alhaisiksi. Kuvassa 1 on esitetty lämpötilakäyrät hevosenpurulantaa sisältävästä kompostista. Lämpötilat olivat melko samankaltaiset tuubeissa 1-5, eivätkä ne nousseet missään vaiheessa $40{ }^{\circ} \mathrm{C}$ :een. Tuubeihin syötetty hevosenlanta oli ilmeisesti jo valmiiksi palanutta, koska sitä oli säilytetty avolantalassa useamman kuukauden ajan. Lämpötilamittausten mukaan näin todella oli, sillä syksyllä 2012 tuubitettu tuore hevosen pellettikuivitettu lanta lämpeni huomattavasti muita komposteja paremmin (Kuva 2). Keväällä 2013 tuubikompostien lämpötilat kohosivat ulkolämpötilojen noustessa. Alkukesästä pintalämpötilat olivat keskimäärin syvälämpötiloja korkeampia, mutta heinäkuun aikana syvälämpötilat kohosivat yleisesti korkeammiksi. Lämpötilat alkoivat laskea säiden viiletessä syyskesän mittaan. Lämpötilat jäivät kokonaisuudessaan edelliskesää alhaisemmiksi. Tuubi 6, johon pakattiin tuoretta pellettikuivitettua hevosenlantaa, lämpeni yli $40{ }^{\circ} \mathrm{C}$ myös toisena vuonna.

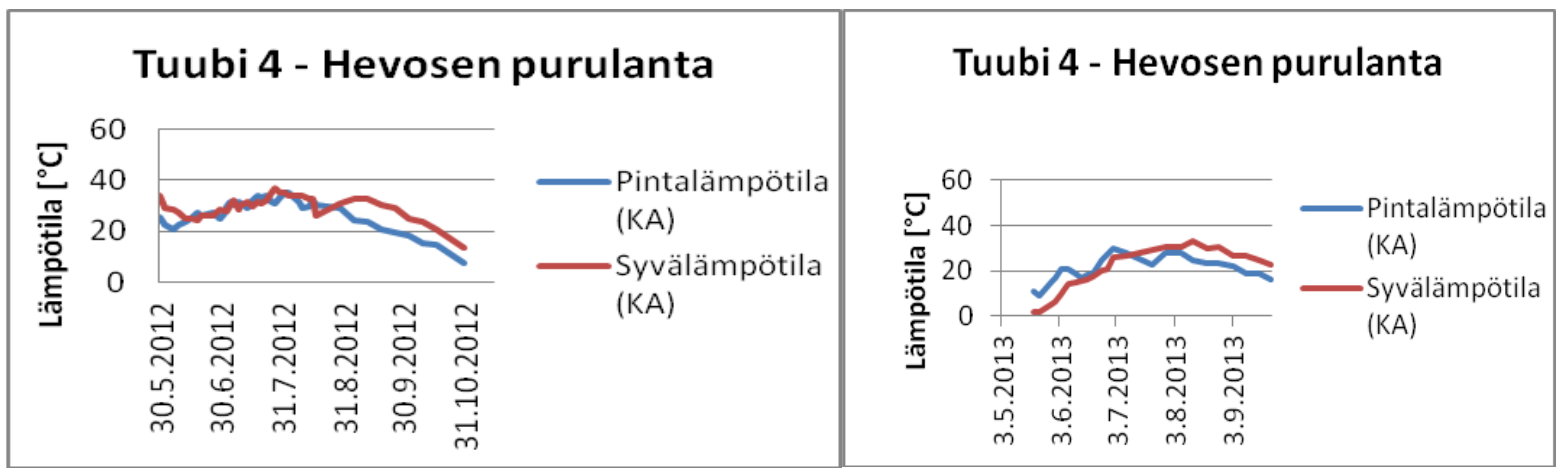

Kuva 1. Avolantalassa säilytetyn hevosenpurulantakompostin lämpötilamittausten keskiarvot tuubin pinnasta $(20 \mathrm{~cm})$ ja sisäosista $(100 \mathrm{~cm})$ kompostin perustamisvuonna 2012 (vas.) ja vuoden kompostoinnin jälkeen kesällä 2013 (oik.). 


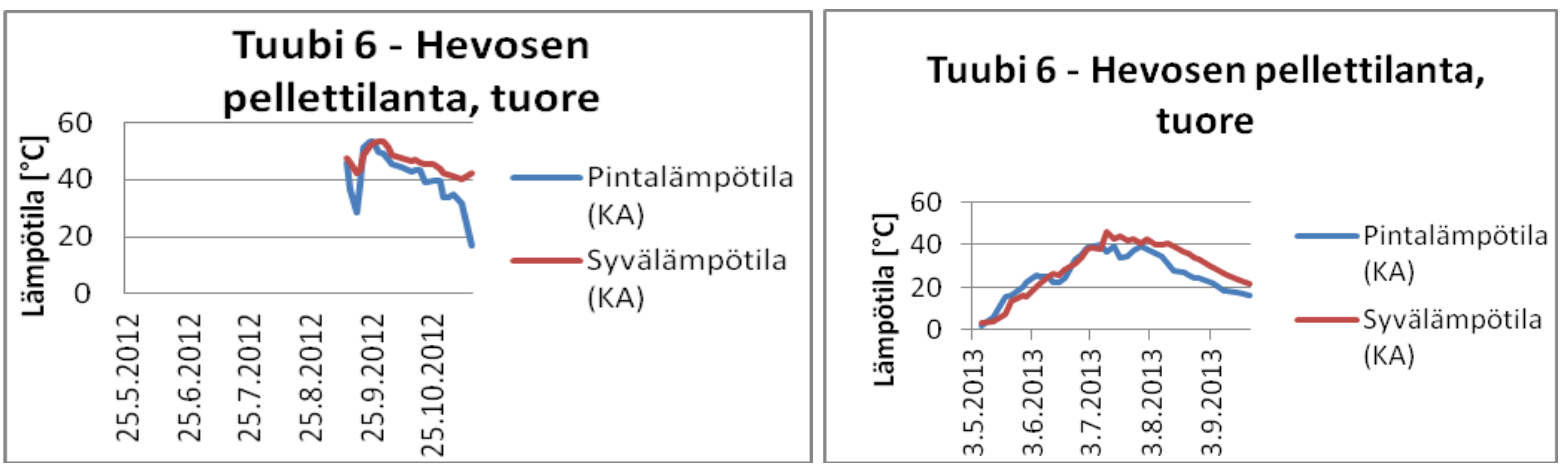

Kuva 2. Tuoreen purupelletillä kuivitetun hevosenlantakompostin lämpötilamittausten keskiarvot tuubin pinnasta $(20 \mathrm{~cm})$ ja sisäosista $(100 \mathrm{~cm})$ kompostin perustamisvuonna 2012 (vas.) ja seuraavana kesänä 2013 (oik.).

Kompostirakenteen tiiviys haittaa kompostoitumisprosessia. Silloin kompostin sekaan ei pääse tarpeeksi ilmaa ja happea, jota aerobiset mikrobit tarvitsevat. Ilmeisesti kahden salaojaputken syöttäminen tuubin sisään ei riittänyt hapen saantiin. Palkeenkielien leikkaamisella havaittiin olevan positiivinen vaikutus tuubien lämpötilan nousuun, mutta koneellisella ilmastuksella ei tuntunut olevan kovin suurta merkitystä. Koneellinen ilmastuksen järjestäminen vaatii työtä ja on hankala toteuttaa maatilalla. Maatalousyrittäjä Markus Eerolan kokemuksen mukaan palkeenkielien leikkaaminen on ratkaisevan tärkeätä kompostin ilmansaannin kannalta (Eerola 2013).

Kananlanta-hevosenlantatuubin (tuubi 1) salaojaputken suulle ja putken sisäpinnoille kertyi kompostinrakentamisvuonna runsaasti valkoista vaahtoa ilmastuksen yhteydessä. Jatkossa myös muiden tuubien, paitsi jo valmiiksi kompostoitunutta hevosenlantaa sisältävän tuubin (tuubi 4), salaojaputken päistä tuli runsaasti tummanruskeaa ja vaahtoavaa nestettä. Nestettä valui erityisesti, jos pellon pinta oli viettävä. Tämän havainnon vahvistivat yrittäjän kokemukset (Eerola 2013). Hapenpuutteen vuoksi tuubien sisällä tapahtui todennäköisesti myös mätänemistä. Tähän viittaa muutamien kompostimassojen pieni kuiva-ainepitoisuus (Taulukko 1), jolloin komposti on ollut liian märkä.

\section{Kompostin koostumus ja kypsyys}

Tuloksista kävi ilmi sekä typen että liukoisen typen alhainen pitoisuus hevosenlannassa (taulukko 1). Tuoreemmassa hevosen pellettilannassa (tuubi 6) liukoisen typen pitoisuus oli kuitenkin vanhempaan purulantaan (tuubi 4) verrattuna huomattavasti korkeampi. Kompostoitavan massan kuivaainepitoisuudet vaihtelivat 22 \%:n ja 33,9 \%:n välillä. Tilavuuspaino nousee kompostoinnin edetessä ja massan painuessa kokoon. Tämä oli havaittavissa useimmissa tuubeissa, mutta hevosenlantakananlantakompostissa tulos oli päinvastainen. Tämä saattaa selittyä epähomogeenisella kompostimassalla. Näytteet pyrittiin ottamaan huolellisesti, mutta on mahdollista, että kahta materiaalia sisältävästä tuubista ei saada täysin edustavaa ja sekoitussuhdetta vastaavaa näytettä.

MTT Sotkamonon tutkimusasemalla tehtiin kompostointikokeita hevosenlannasta myös vuonna 2001 (Sihto 2001). Lantojen kuivikemateriaaleina olivat tuolloin turve, kutterinpuru, sahajauho, kutterinpuru-turve ja sahanjauho-turve. Kompostit tehtiin peittämättömiin kasoihin ja niitä käännettiin kahdesti kompostointiaikana. Kompostit olivat perustettaessa kuivempia (ka-\%:t 32,0 - 43,0) kuin tämän tutkimuksen kompostit. Kokonaistypen ja liukoisen typen pitoisuudet sekä $\mathrm{pH}$ olivat samalla tasolla tämän tutkimuksen materiaalien kanssa lukuun ottamatta kananlantasekoitteista kompostia, jonka typpipitoisuus oli suurempi. 
Taulukko 1. Laboratorioanalyysien keskeisimmät tulokset eri kompostituubeista perustamisen yhteydessä vuonna 2012 ja vuoden kompostoinnin jälkeen vuonna 2013. Purulanta-mädäteseoksesta ei otettu näytettä perustamisvaiheessa.

\begin{tabular}{|c|c|c|c|c|c|c|c|c|c|c|c|c|c|c|}
\hline \multirow{2}{*}{$\begin{array}{l}\text { Kompostoitava } \\
\text { materiaali (tuubin } \\
\text { nro) }\end{array}$} & \multicolumn{2}{|c|}{ TS \% } & \multicolumn{2}{|l|}{$\mathrm{pH}$} & \multicolumn{2}{|c|}{\begin{tabular}{|l|} 
Tilavuuspaino \\
$\mathrm{g} / \mathrm{l}$
\end{tabular}} & \multicolumn{2}{|c|}{$\begin{array}{l}\mathrm{N}_{\text {tot }} \\
\mathrm{g} / \mathrm{kg} \mathrm{ka}\end{array}$} & \multicolumn{2}{|c|}{$\begin{array}{l}\mathrm{N}_{\text {liuk }} \\
\mathrm{g} / \mathrm{kg} \mathrm{ka}\end{array}$} & \multicolumn{2}{|c|}{$\begin{array}{l}\mathrm{P}_{\text {tot }} \\
\mathrm{g} / \mathrm{kg} \mathrm{ka}\end{array}$} & \multicolumn{2}{|l|}{$\mathrm{C} / \mathrm{N}$} \\
\hline & 2012 & 2013 & 2012 & 2013 & 2012 & 2013 & 2012 & 2013 & 2012 & 2013 & 2012 & 2013 & 2012 & 2013 \\
\hline $\begin{array}{l}\text { Hevosen purulan- } \\
\text { ta +kananlanta (1) }\end{array}$ & 30,5 & 29,5 & 46 & 8,67 & 494,00 & 466,3 & 30,1 & 23,19 & 18,8 & 7,42 & 9,01 & 8,75 & 13,71 & 22,60 \\
\hline $\begin{array}{l}\text { Hevosen olki- } \\
\text { turvelanta (2) }\end{array}$ & 25,1 & 28,7 & 7,73 & 7,90 & 444 & 463,9 & 15,2 & 17,74 & 2,91 & 1,36 & 2,45 & 3,14 & 20,71 & 15,55 \\
\hline $\begin{array}{l}\text { Hev. purulanta + } \\
\text { naudanlanta (3) }\end{array}$ & 22 & $\underline{0,8}$ & 69 & 7,11 & 419 & 500,5 & 19,3 & 17,39 & 3,87 & 1,73 & 3,12 & 2,45 & 24,10 & 22,58 \\
\hline $\begin{array}{l}\text { Hevosen purulan- } \\
\text { ta (4) }\end{array}$ & 27 & 28,9 & 7,31 & 7,86 & 416 & 396,9 & 11,3 & 9,77 & 1,85 & 0,59 & 3,14 & 1,84 & 38,65 & 38,55 \\
\hline $\begin{array}{l}\text { Hevosen purulan- } \\
\text { ta+mädäte (5) }\end{array}$ & & 29,5 & & 7,7 & & 449,41 & & 11,86 & & 0,85 & & 2,07 & & 24,1 \\
\hline $\begin{array}{l}\text { Hevosen pelletti- } \\
\text { kuivitettu lanta } \\
\text { (tuore) (6) }\end{array}$ & 33,9 & 31,8 & 7,7 & 8,52 & 295,6 & 454,9 & 13,8 & 11,21 & 4,04 & 1,51 & 2,6 & 1,79 & 32,02 & 29,20 \\
\hline
\end{tabular}

Mikäli kompostoinnissa pyritään maksimoimaan jätteen määrällinen häviäminen, paras hiilityppisuhde on noin 25 - 30. Viljelykäytössä sen sijaan optimaalinen hiilityppisuhde on alle 20, jolloin typpi vapautuu kasvien käyttöön nopeasti. (Briddlestone et al., 1987). Tässä tutkimuksessa ainoastaan vuoden kompostoituneella olki-turvekuivitetulla hevosenlannalla $\mathrm{C} / \mathrm{N}$-suhde laski alle 20:n. Se oli vuonna 2013 15,5 (Taulukko 1). Hevosen purulantakompostin hiilityppisuhde oli vuoden kompostoinnin jälkeen 38,6 ja hevosen puupellettilantakompostin 29,2. Benito ym. (2009) mukaan hiilityppisuhteen käyttäminen hevosenlantaa sisältävän kompostin arvioinnissa ei ole täysin luotettavaa hevosenlannan korkean kuivikepitoisuuden ja siten korkean hiili-typpisuhteen vuoksi. Kuivikelaatu vaikuttaa lannan hiili-typpisuhteeseen ja muihin ominaisuuksiin voimakkaasti. Turpeella ja oljella se on alhaisin, alle 100, mutta purulla jopa 600 (Airaksinen 2006). Sihdon (2001) kokeissa yhden kesän kompostoinnin jälkeen C/N-suhteet olivat korkeampia kuin tässä tutkimuksessa, sahanjauhokompostissa 57,3 ja sahanjauho-turvekompostissa 58,7. Lämpötilat nousivat Sihdon tutkimuksessa tämän tutkimuksen tuubikomposteja korkeammiksi, turvekompostia lukuun ottamatta $60{ }^{\circ} \mathrm{C}$ :een.

Kypsässä kompostissa ammoniumtypen pitoisuus on pieni (Bernal 1998). Tutkitun kompostin (tuubi 4) ammoniumtypen määrä jäi tässä tutkimuksessa Kjehldal-menetelmällä alle määritysrajan suurillakin näytteen pitoisuuksilla, joten se on hyvin pieni. Tämä viittaa tutkimuskompostin kypsyyteen. Haihtuvat rasvahapot ovat kompostoitumisen tuotteita, jotka myöhemmin prosessissa muutetaan edelleen toisiksi yhdisteiksi. Haihtuvien rasvahappojen puute kompostissa viittaa siten kompostin kypsyyteen. Tämän tutkimuksen määrityksessä ei löytynyt haihtuvia rasvahappoja.

Alustavasti arvioituna kasvitoksisuuskokeen tulosten itävyydessä ei ilmennyt eroja, mutta tulosta ei ole vielä vahvistettu tilastoanalyysillä. Vihanneskrassilla oli havaittavissa kompostin lannoittavaa vaikutusta, sillä komposti-vesiliuoksella kastellut siemenet näyttivät kasvattavan pidemmän juuren ja verson. Tämäkin viittaisi siihen, että komposti ei aiheuttanut kasvitoksisuutta. Kiinankaalilla tulokset eivät olleet aivan yhtä selkeät, mutta senkään tulokset eivät viittaa kasvitoksisuuteen.

\section{Lannoituskoe}

Kokeessa lannoittamaton koejäsen erottui selvästi heikoimpana orastumisesta asti. Sen kasvusto oli muita koejäseniä vaaleampaa ja lyhyempää. Suojaviljana olleesta ohrasta saatiin paras sato (4940 kg/ha) koejäsenestä 2, joka oli lannoitettu kompostilla ja typpitäydennyksellä. Lähes yhtä hyvän sadon antoi väkilannoitus (4671 kg/ha). Pelkällä kompostilannoituksella saatiin 3202 kg/ha, kun taas koko- 
naan lannoittamattoman koejäsenen hehtaarisato jäi 1789 kg:aan. Koe jatkuu kesällä 2014 nurmen korjuulla. Maa-analyysien tulokset kootaan kokeen päätyttyä.

\section{Johtopäätökset}

Tutkimuksella haluttiin saada tietoa erityisesti puuperäisen kompostin maatumisesta tuubissa sekä tuubikompostointimenetelmän käyttökelpoisuudesta esimerkiksi maatilalla. Kokeesta saatiin käyttökelpoista tietoa jo yhden vuoden perusteella. Koetta jatketaan vielä kesään 2014, jonka jälkeen valmistuvat lopulliset tulokset.

Vaikka kompostien lämpötilat eivät kohonneet kovin korkeiksi, kompostoituminen vaikutti edenneen vuodessa hyvin. Tästä ovat merkkinä C/N-suhteen pieneneminen, tilavuuspainon aleneminen ja kypsyystestien tulokset. Kokeen jatkuessa vielä vuodella saadaan lisää tietoa kompostien koostumuksen muutoksista. Tuubitusta harjoittavan yrittäjän mukaan purulannan on hyvä antaa kompostoitua kaksi vuotta. Jälkikompostoituminen olisi eduksi tuubien purkamisen jälkeen. (Eerola 2013) Yrittäjän arvion ja 7 vuoden kokemuksen perusteella kompostin levityksellä on savimailla selvä maanparannusvaikutus. Tuubikompostointi antaa myös pelivaraa kompostin levittämiseen. Tuubit voivat olla paikallaan useita vuosia ja ne voidaan levittää silloin kun viljelyskiertoon sopii.

Kompostia varten ei tarvita tiivistä alustaa tai valuma-altaita, mutta pellon pinnan on oltava tasainen, sillä viettävällä pellolla ilmastusputkien päistä valuu nestettä. Itse tuubin rakentaminen käy pakkauskoneella nopeasti. Yrittäjä voi esimerkiksi hakea lannan siirtolavoilla talleilta, ja tuubittaa isomman erän kerralla. Menetelmänä tuubikompostointi sopii maatilan yhteyteen, jossa komposti voidaan perustaa samalle pellolle, johon se levitetään lannoitteeksi. Tuubikompostoinnin kustannukset arvioidaan tämän tutkimuksen päätyttyä.

\section{Kirjallisuus}

Airaksinen, S. 2006. Bedding and Manure Management in Horse Stables - Its Effect on Stable Air Quality, Paddock Hygiene and the Compostability and Utilization of Manure, 2006. Väitöskirja. Kuopion yliopiston julkaisuja C. Luonnontieteet ja ympäristötieteet 190.

Anon. 2013. Murska esite. http://www.murskabiopacker.fi/fin/esitteet2011/Murska_fi11112013.pdf

Eerola, M. 2013. Suullinen tiedonanto 15.12.2013.

Benito, M., Masaquer, A., Moliner, A., Hontoria, C. \& Almorox, J. 2009: Dynamics of pruning waste and spent horse litter co-composting as detemined by chemical parameters. -Bioresour.Technol., 100, 1, 497-500 Bernal, M. P., Paredez, C., Sánchez-Monedero, M. A. \& Cegarra, J. 1998: Maturity and stability parameters of composts prepared with a wide range of organic wastes. -Bioresource Technology 63, 91-99.

Briddlestone A.J., Gray K.R. \& Day C.A. 1987. Composting and straw decomposition. Environmental Biotechnology. C.S. Forster and D.A.J. Wase (Eds.), Ellis Horwood 135-175.

Epstein, E. 1997: The Science of Composting. -Technomic Publishing Company.

Hollmen, M. 2010. Hevostoiminnan ympäristökysymyksiä Satakunnassa ja Varsinais-Suomessa. Teho hankkeen julkaisuja 2/2010. Varsinais-Suomen $\quad$ ELY-keskus. $31 \quad$ s. http://www.ymparisto.fi/download/noname/\%7BE62E05D9-5D3C-4D67-A6AA-8AAE20F8A135\%7D/54728

Itävaara, M., Vikman, M., Kapanen, A. Venelampi, O. \& Vuorinen, A. 2006. Kompostin kypsyystestit. Menetelmäohjeet. VTT tiedotteita 2351. Espoo.

Pesonen I., Virtanen H. \& Jansson H. 2008. Hyvinvoiva, turvallinen ja ympäristöystävällinen talli- opas vastuulliseen tallitoimintaan. MTT. Agropolis Oy. Forssa. Saatavissa: http://www.hippos.fi/files/1373/talliopas08.pdf

Sihto, U. 2001. Hevostallien erilaiset kuivikeratkaisut, lannan hyötykäyttö ja kompostointi. Tutkimusraportti joulukuu 2001. Kainuun maaseutukeskus. 36 s. 